\title{
MORTALIDADE DA PESCADA-FOGUETE, Macrodon ancylodon
}

(Recebido em 16/8/68)

\author{
N. Yamaguti
}

Instituto Oceanográfico da Universidade de São Paulo

\begin{abstract}
SYNOPSIS
The instantaneous mortality coefficient $(F+M)$ of the commercial weakfish, Macrodon ancylodon (Bloch, 1801) caught by trawls along southern Brazilian coast (from latitude $28^{\circ} \mathrm{S}$ to $34^{\circ} \mathrm{S}$ ), was computed by means of the annual catch variation (in number) by age per fishing effort from March 1961 to December 1964.

The instantaneous mortality coefficient mean values for female and male was respectivelly 1.31 and 1.53 .

One year old recruits appear in the landings and the mesh selectivity operates on fish up to three years old.

Three-year old class predominates in the landings.
\end{abstract}

\section{INTRODUÇÃO}

No estudo da dinâmica de uma população, em que procuramos estimar a dimensão de um estoque de peixes e cálculo do máximo de produção em equilíbrio, os principais parâmetros que precisam ser determinados são a densidade de população, taxa de crescimento do peixe, recrutamento, taxa de mortalidade, e potencial das classes anuais.

Nêste trabalho procuramos estimar o coeficiente instantâneo de mortalidade total (mortalidade causada pela pesca mais a mortalidade causada pelos fatôres naturais) anual da população de pescada-foguete $M a$ crodon ancylodon (BLOCH, 1801), capturada ao longo da costa sul de Santa Catarina e do Rio Grande do Sul.

\section{MATERIAL E MÉTODOS}

Este trabalho está baseado em 139 amostras, com cêrca de 100 peixes cada, que foram retiradas durante o período de março de 1961 a dezembro de 1964, das capturas efetuadas pelos barcos de pesca (parelhas de arrasto) entre as latitudes $28^{\circ} \mathrm{S}$ e $34^{\circ} \mathrm{S}$. A idade do peixe foi determinada pela contagem dos anéis translúcidos apresentados pelos otolitos (YAMAgUTI \& SANTos, 1966).

A Figura 1 apresenta o número médio bimensal de peixes, por idade, capturado por hora-lance $(\mathrm{kg}$ por hora).

Publ, n.o 269 do Inst. Ocean. da USP.
O coeficiente instantâneo de mortalidade foi calculado tomando-se, por base o número médio de peixes por idade, capturados por unidade de esfôrço (Beverton \& Holt, 1957). Como a produção por unidade de esfôrço varia durante o ano, aumentando durante o início e fim do ano, caindo nos meses intermediários, por causa da dispersão dos peixes, que ocorre durante a migração (SANtos \& YAMAguti, 1965; YAMaguti, 1967), não foi possível a obtenção da mortalidade total bimensal. Por isso calculamos, as mortalidades anuais, tomando amostras coletadas no mesmo período do ano, porém diferente, isto é, determinamos o número médio de indivíduos de uma determinada classe de idade, coletadas por hora-lance, por exemplo, nos meses de janeiro e fevereiro de 1962 e fizemos o mesmo em janeiro e fevereiro de 1963; a diminuição do número médio, é a mortalidade. Para evitar o efeito de seletividade, calculamos a mortalidade utilizando sòmente as classes de idade totalmente recrutadas (Tabela I).

Para determinarmos as classes de idade predominante no capturado analisamos o número médio anual de peixes por idade, capturado por hora-lance (Fig. 2).

\section{CONCLUSÕES}

Analisando os números bimensais e anuais (captura por hora-lance, por idade e sexo) de pescada-foguete - Macrodon ancylodon, capturada ao longo da costa da região centro-sul do Brasil, entre as lati. 


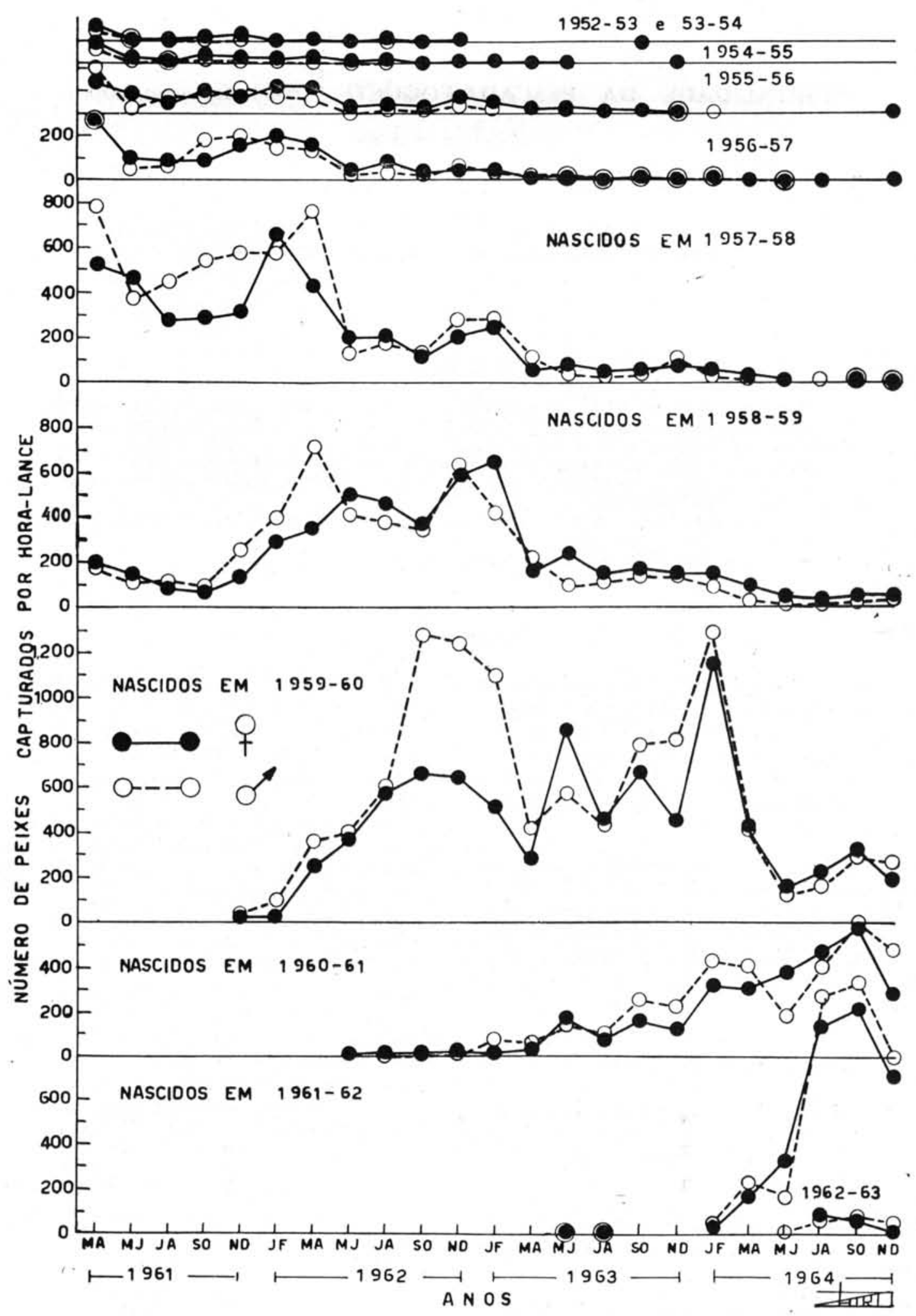

Fig. 1 - Número bimensal de peixes capturados por unidade de esfôrço (hora-lance) por classe de idade. 
TABELA I - Coeficiente instantâneo de mortalidade total anual, por classe de idade $(53 / 54 . \ldots . .$. , significa classe dos indivíduos nascidos no fim de 1953 e no principio de 1954), calculados utilizando amostras coletadas, por exemplo em janeiro e fevereiro de 1961 e de 1962, e assim sucessivamente

FEMEA: $1961-1962$

$\begin{array}{lcccccccc}\text { Classe } & \text { jan-fev } & \text { mar-abr } & \text { mai-jun } & \text { jul-agô } & \text { set-out } & \text { nov-dez } & \text { média } & \text { média anual } \\ \mathbf{5 2 / 5 3} & - & 1,49 & - & 0,87 & - & - & 1,18 & \\ 53 / 54 & - & 1,17 & 1,07 & 0,17 & 1,56 & 0,89 & 0,97 & \\ 54 / 55 & - & 0,91 & 0,88 & - & 1,94 & 0,90 & 1,16 & 0,94 \\ 55 / 56 & - & 0,81 & 2,06 & 0,68 & 1,63 & 0,42 & 1,12 & \\ 56 / 57 & - & 0,57 & 1,09 & 0,03 & 1,51 & 1,04 & 0,85 & \\ 57 / 58 & - & 0,19 & 0,87 & 0,33 & 0,95 & 0,44 & 0,56 & \end{array}$

$1962-1963$

$\begin{array}{lccccccc}54 / 55 & 1.56 & 2,60 & 1,96 & - & - & 1,91 & 2,01 \\ 55 / 56 & 1,34 & 2,81 & 0,09 & 2,56 & 0,89 & 2,49 & 1,70 \\ 56 / 57 & 1,34 & 2,86 & 1,16 & 2,88 & 1,00 & 1,41 & 1,78 \\ 57 / 58 & 0,98 & 2,00 & 1,06 & 1,64 & 1,20 & 1,06 & 1,32 \\ 58 / 59 & - & 0,86 & 0,72 & 1,15 & 0,69 & 1,36 & 0,96\end{array}$

$1963-1964$

$\begin{array}{lccccccc}55 / 56 & - & - & - & - & - & 1,22 & 1,22 \\ 56 / 57 & 2,32 & 0,67 & 2,02 & 1,10 & - & 2,34 & 1,69 \\ 57 / 58 & 1,66 & 0,82 & 2,29 & 1,92 & 0,99 & 3,38 & 1,84 \\ 58 / 59 & 1,42 & 0,56 & 1,46 & 1,47 & 1,24 & 1,17 & 1,22 \\ 59 / 60 & - & - & 1,69 & 0,76 & 0,73 & 0,85 & 1,01\end{array}$

MACHO: $1961-1962$

$\begin{array}{lcccccccc}\text { Classe } & \text { Jan-fev } & \text { mar-abr } & \text { mai-jun } & \text { jul-agô } & \text { set-out } & \text { nov-dez } & \text { média } & \text { média anual } \\ 54 / 55 & - & 1,93 & - & - & 1,57 & - & 1,75 & \\ 55 / 56 & - & 1,65 & 1,77 & 2,48 & 2,28 & 1,34 & 1,90 & 1,40 \\ 56 / 57 & - & 0,69 & 1,10 & 1,05 & 2,43 & 1,26 & 1,31 & \\ 57 / 58 & - & 0,03 & 1.11 & 0,94 & 1,46 & 0,75 & 0,86 & \end{array}$

$1962-1963$

$\begin{array}{lccccccc}55 / 56 & 1,94 & - & - & 2,22 & - & 1,17 & 1,78 \\ 56 / 57 & 1,66 & 2,24 & 1,80 & 1,45 & 1,67 & 1,24 & 1,68 \\ 57 / 58 & 0,72 & 2,00 & 1,10 & 1,93 & 1,22 & 1,14 & 1,35 \\ 58 / 59 & - & 1,21 & 1,46 & 1,29 & 0,89 & 1,58 & 1,29\end{array}$

$1963-1964$

$\begin{array}{lcccccccc}55 / 56 & 1,59 & - & - & - & - & - & 1,59 & \\ 56 / 57 & 1,32 & - & 1,32 & - & - & - & 1,32 & \\ 57 / 58 & 2,63 & 3,73 & 1,31 & 2,26 & 2,80 & 3,96 & 2,78 & \\ 58 / 59 & 1,55 & 1,16 & 1,31 & 1,84 & 1,91 & 1,27 & 1,51 & \\ 59 / 60 & - & 0,03 & 0,60 & 0,97 & 0,98 & 1,09 & 0,73 & \end{array}$




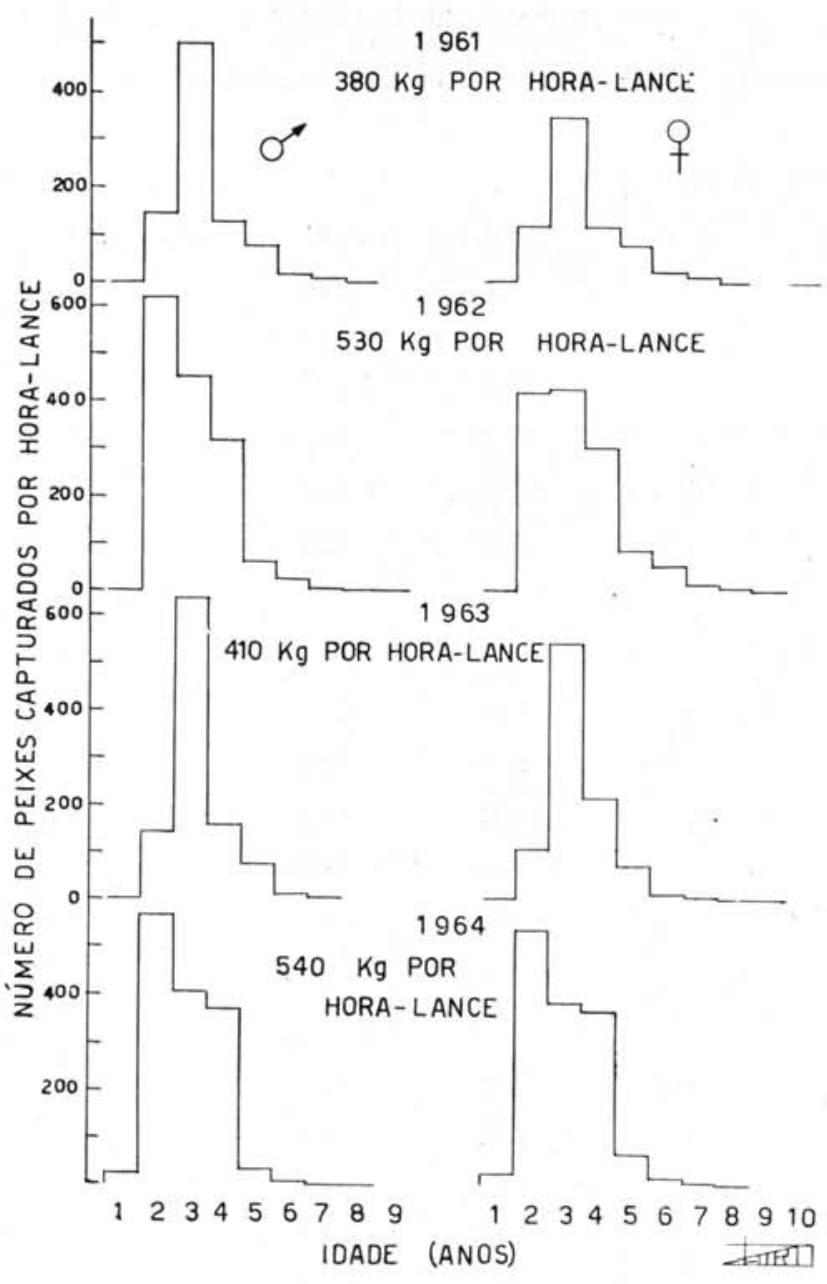

Fig. 2 - Número anual de peixes capturados por unidade de esfôrço, por classe de idade e produção anual.

tudes $28^{\circ} \mathrm{S}$ e $34^{\circ} \mathrm{S}$, no período de 1961 a 1964 , concluímos:

1 - Os peixes recrutas começam a aparecer, em pequeno número, no desembarcado, com um ano de idade (Fig. 1).

2 - O número de recrutas de uma mesma clas. se anual aumenta, devido à seletividade das malhas da rêde (diminuição do escape) (Richardson \& SANTos, 1962) durante três anos; a seguir o número de peixes diminui por causa da mortalidade.

3 - O coeficiente instantâneo de mortalidade total anual foi:

\begin{tabular}{|c|c|c|}
\hline Classe anual & Macho & Fêmea \\
\hline $53 / 54$ & - & 0,94 \\
\hline $54 / 55$ & 1,75 & 1,58 \\
\hline $55 / 56$ & 1,83 & 1,42 \\
\hline $56 / 57$ & 1,48 & 1,46 \\
\hline $57 / 58$ & 1,41 & 1,10 \\
\hline $59 / 60$ & 0,73 & 1,01 \\
\hline Média & 1,53 & 1,31 \\
\hline Média geral & & \\
\hline
\end{tabular}

Para têrmos idéia de mortalidade verificada em outras espécies citamos alguns autôres: Postuma (1963) encontrou para o arenque (herring) nos anos de 1956 a 1960 o coeficiente instantâneo de mortalidade total média de 1,20; Hennemuth (1961), para o "yellow fin", 1,72; Ketchen (1964), para o "cod" de 1,05 a 1,53; SAntos (1968), para o goete, 1,42.

4. - A classe de 3 anos constitui a classe de idade mais importante no capturado, estando bem representada, mesmo quando não é a classe anual predominante (Fig. 2).

5 - Durante os anos em que houve grande recrutamento (1962 e 1964) as produções por unidade de esfôrço foram mais elevadas (respectivamente 530 a $540 \mathrm{~kg}$ ) e nos anos de pequeno recrutamento, mais baixas $(380$ e $4.10 \mathrm{~kg})$, respectivamente em 1961 e 1963 (Fig. 2).

\section{B I B L IO G R A F I A}

Beverton, R. J. H. \& Holt, S. J.

1957. On the dynamics of exploited fish populations. Fishery Invest., Lond., ser. 2 , vol. 19.

HENNEMUTH, R. C.

1961. Year class abundance, mortality and yield-per-recruit of yellow fin tuna in the Eastern Pacific Ocean, 1954-1959. Bull. inter-Am. trop. Tuna Commn, vol. 6 , n. 1 , p. $1-32$.

KETCHEN, K. S.

1964. Preliminary results of studies on growth and mortality of Pacific cod (Gadus macrocephalus) in Hecate Strait, British Columbia. J. Fish. Res. Bd Can., vol. 21, n. ${ }^{\circ}$, p. $1051-1067$.

Postuma, K. H.

1963. The catch per unit effort and mortality rates in the Southern Bight and Channel herring fisheries. Rapp. P.-v. Réun. Cons. perm. int. Explor. Mer, vol. 154, p. 190-197.

Richardson, I. D. \& Santos, E. P. dos

1962. Note on the selectivity of meshes used by the Santos fishing fleet. Bolm Inst. oceanogr. S Paulo, vol. 12, n. ${ }^{\circ} 1, \mathrm{p}$. 33-52.

Santos, E. P. dos

1968. Estudo populacional do goete, Cynoscion petranus (Ribeiro, 1915). Ciênc. Cult. S Paulo, vol. 20, n. $^{\circ}$ 2, p. 319.

Santos, E. P. dos \& Yamaguti, N.

1965. Migração da pescada-foguete, Macrodon ancylodon. Bolm Inst. oceanogr. S Paulo, vol. 14, p. 129-131.

YAMAGUTI, N.

1967. Desova da pescada-foguete, Macrodon ancylodon. Bolm Inst. oceanogr. S Paulo, vol. 16, n..$^{\circ}$ único, p. 101-106.

Yamaguti, N. \& Santos, E. P. dos

1966. Crescimento da pescada-foguete, Macrodon ancylodon: aspecto quantitativo. Bolm Inst. oceanogr. S Paulo, vol. 15, n. ${ }^{\circ} 1$, p. $75-78$. 